\title{
Dibucaine Toxicosis in a Dog
}

\author{
Andrew S. Hanzlicek • Deon Van der Merwe
}

Published online: 12 March 2010

(C) American College of Medical Toxicology 2010

\begin{abstract}
Introduction Dibucaine is a potent, long-lasting local anesthetic (LA). Topical dibucaine ointments are marketed directly to consumers in the USA without prescription. Dibucaine ointment is intended to treat discomfort associated with sunburn, eczema, minor rashes, minor scratches, insect bites, and poison ivy and is used alone or in combination with other active ingredients to treat pain associated with hemorrhoids or other anorectal disorders. Oral dibucaine toxicosis has been reported in children and includes gastrointestinal upset and neurologic and cardiovascular dysfunction.

Case Report An 18-month-old, female, Parson Russell terrier ingested approximately $23 \mathrm{~g}$ of $1 \%$ dibucaine ointment (approximately $38 \mathrm{mg} / \mathrm{kg}$ dibucaine) recommended to the owner for the treatment of hemorrhoids. Onset and resolution of clinical signs were relatively rapid, $5 \mathrm{~min}$ and $60 \mathrm{~min}$, respectively. Clinical signs included vomiting, ptyalism, whole-body muscle fasciculations, disorientation, and severe ataxia.

Discussion Oral dibucaine toxicosis in dogs is similar to oral dibucaine toxicosis in children. Dibucaine ointment poses a real and potentially serious toxicological risk to pets and thus should be stored in a safe location.
\end{abstract}

Keywords Canine $\cdot$ Local anesthetic $\cdot$ Neurology Cardiology $\cdot$ Hemorrhoid

\footnotetext{
A. S. Hanzlicek $(\bowtie)$

Department of Clinical Sciences, College of Veterinary Medicine, Kansas State University,

1800 Denison Ave,

Manhattan, KS 66506, USA

e-mail: ahanzlic@vet.k-state.edu

D. Van der Merwe

Department of Diagnostic Medicine and Pathobiology,

College of Veterinary Medicine, Kansas State University,

1800 Denison Ave,

Manhattan, KS 66506, USA
}

\section{Case Report}

A 6-kg, 18-month-old spayed, female Parson Russell terrier presented on emergency basis to Kansas State University, College of Veterinary Medicine for known ingestion of $23 \mathrm{~g}$ (based on $5 \mathrm{~g}$ left over in a 28 -g tube that was full before ingestion of contents by the dog) of $1 \%$ dibucaine ointment (Dibucaine Ointment USP, 1\%, Perrigo, Allegan, MI), approximately $30 \mathrm{~min}$ previously. The inactive ingredients listed on the package insert were acetone sodium bisulfate (as a preservative), anhydrous lanolin, and white petroleum. The ointment is odorless, with a very slightly yellowish color and consistency typical for white petroleum skin care products. The owner's physician had recommended the dibucaine ointment the previous day for hemorrhoids. The owner found the dog after only a few minutes of the dog being unobserved along with the chewed dibucaine tube. The dog began hypersalivating and vomited soon after it was found by the owner. The patient continued to vomit multiple times over the next $15 \mathrm{~min}$. The appearance of the vomitus was consistent with that of the appearance of the dibucaine ointment. Approximately $5 \mathrm{~min}$ after ingestion, the owner noticed whole body muscle twitching and disorientation. Over the next $15 \mathrm{~min}$, the muscle twitching and disorientation progressively worsened, and the patient became ataxic to the point of being non-ambulatory. Upon presentation, the dog exhibited ptyalism, fine whole-body muscle fasciculations, and appeared disoriented. On neurologic examination, the dog was unable to walk more than a few steps due to severe ataxia. Conscious proprioception, assessed by flexing the foot so that the dorsal surface was on the floor, appeared normal as the dog immediately replaced the foot to the correct position. Cranial nerves were assessed by observing appropriate responses to visual and auditory stimuli, the presence of facial sensation and facial symmetry, the presence of a physiologic nystagmus and absence of a spontaneous nystagmus, the absence of a strabismus, the presence of a normal indirect and direct 
pupillary light reflex, and a normal gag reflex. No cranial nerve deficits were detected. Spinal reflexes were not assessed due to the lack of proprioceptive deficits. The rest of the physical examination was unremarkable. After the initial examination, an intravenous (IV) catheter was placed in the left cephalic vein, and the patient received an activated charcoal $(1.5 \mathrm{~g} / \mathrm{kg})$, sorbitol $(1.5 \mathrm{~g} / \mathrm{kg})$, and kaolin $\left(937 \mathrm{mg} / \mathrm{kg}\right.$ ) suspension (Toxiban ${ }^{\circledR}$, Vet-A-Mix, Shenandoah, IA) via orogastric tube. An ECG showed a normal sinus rhythm, and indirect arterial systemic blood pressure (Doppler, Parks Medical Electronics, Aloha, OR) was $135 \mathrm{mmHg}$ (Normal, 90-140 mmHg). Serum biochemistry and complete blood count were unremarkable (Table 1). Shortly after administration of activated charcoal and placement of an IV catheter, approximately $1 \mathrm{~h}$ after ingestion of dibucaine ointment, a neurologic examination revealed normal ambulation and resolution of whole-body muscle fasciculations. In addition, ptyalism had almost completely resolved. The dog was placed in intensive care for continued monitoring, and IV fluids (Lactated Ringer's) were administered $(4 \mathrm{ml} / \mathrm{kg} / \mathrm{h})$ over the next $12 \mathrm{~h}$. Maropitant citrate $\left(C^{2}\right.$ renia ${ }^{\circledR}$, Pfizer Animal Health, New York, $\mathrm{NY})$ was administered ( $1 \mathrm{mg} / \mathrm{kg}$, subcutaneously) approximately $2 \mathrm{~h}$ after ingestion of dibucaine ointment due to perceived nausea (mild hypersalivation and lip licking). The dog recovered uneventfully and was discharged the following day. Follow-up with the owner via telephone 1 week later revealed that the patient continued to do well although mild lethargy was reported for $48 \mathrm{~h}$ after discharge from the hospital.

\section{Discussion}

Local anesthetics (LAs) cause reversible inhibition of axonal voltage-gated sodium channels inhibiting depolar-
Table 1 Serum biochemistry and complete blood count results $m g$ milligram; $d L$ deciliter; $g$ gram; $L$ liter; $m m o l$ millimole; $U$ unit; $K 1,000 ; \mu l$ microliter; $M$ one million; $f L$ femtoliter

\begin{tabular}{|c|c|c|c|}
\hline Parameter & Patient Results & Reference Interval & Units \\
\hline Glucose & 137 & $73-113$ & $\mathrm{mg} / \mathrm{dL}$ \\
\hline Blood urea nitrogen & 24 & $9.0-33.0$ & $\mathrm{mg} / \mathrm{dL}$ \\
\hline Creatinine & 0.7 & $0.5-1.5$ & $\mathrm{mg} / \mathrm{dL}$ \\
\hline Total protein & 6.2 & $5.4-7.6$ & $\mathrm{~g} / \mathrm{dL}$ \\
\hline Albumin & 4 & $3.4-4.2$ & $\mathrm{~g} / \mathrm{dL}$ \\
\hline Globulin & 2.2 & $1.3-3.2$ & $\mathrm{~g} / \mathrm{dL}$ \\
\hline Total calcium & 10.9 & $9.7-12.1$ & $\mathrm{mg} / \mathrm{dL}$ \\
\hline Phosphorous & 3.5 & $2.4-6.4$ & $\mathrm{mg} / \mathrm{dL}$ \\
\hline Sodium & 148 & $147-154$ & $\mathrm{mmol} / \mathrm{L}$ \\
\hline Potassium & 4.2 & $3.6-5.3$ & $\mathrm{mmol} / \mathrm{L}$ \\
\hline Chloride & 112 & $108-118$ & $\mathrm{mmol} / \mathrm{L}$ \\
\hline Bicarbonate & 22 & $18-29$ & $\mathrm{mmol} / \mathrm{L}$ \\
\hline Alanine transaminase & 47 & $28-171$ & $\mathrm{U} / \mathrm{L}$ \\
\hline Alkaline phosphatase & 54 & $1-142$ & $\mathrm{U} / \mathrm{L}$ \\
\hline Creatine kinase & 97 & $128-328$ & $\mathrm{U} / \mathrm{L}$ \\
\hline Total bilirubin & 0.1 & $0.1-0.3$ & $\mathrm{mg} / \mathrm{dL}$ \\
\hline Cholesterol & 211 & $133-394$ & $\mathrm{mg} / \mathrm{dL}$ \\
\hline Leukocyte count & 6.2 & $6.0-17.0$ & $\mathrm{~K} / \mu \mathrm{L}$ \\
\hline Segmented neutrophil concentration & 3.5 & $3.0-11.5$ & $\mathrm{~K} / \mu \mathrm{L}$ \\
\hline Band neutrophil concentration & 0 & $0-0.3$ & $\mathrm{~K} / \mu \mathrm{L}$ \\
\hline Lymphocyte concentration & 1.8 & $1.5-5.0$ & $\mathrm{~K} / \mu \mathrm{L}$ \\
\hline Monocyte concentration & 0.4 & $0.1-0.8$ & $\mathrm{~K} / \mu \mathrm{L}$ \\
\hline Eosinophil concentration & 0.4 & $0-0.75$ & $\mathrm{~K} / \mu \mathrm{L}$ \\
\hline Basophil concentration & 0 & $0-0.1$ & $\mathrm{~K} / \mu \mathrm{L}$ \\
\hline Erythrocyte concentration & 7.15 & $5.5-8.5$ & $\mathrm{M} / \mu \mathrm{L}$ \\
\hline Hemoglobin & 17.7 & $12.0-18.0$ & $\mathrm{~g} / \mathrm{dL}$ \\
\hline Hematocrit & 50 & $37-55$ & $\%$ \\
\hline Mean red blood cell volume & 69 & $62-76$ & $\mathrm{fL}$ \\
\hline Mean red blood cell hemoglobin concentration & 36 & $33-37$ & $\mathrm{~g} / \mathrm{dL}$ \\
\hline Platelet concentration & 256 & $200-500$ & $\mathrm{~K} / \mu \mathrm{L}$ \\
\hline Plasma protein (refractometry) & 7 & $6.0-8.0$ & $\mathrm{~g} / \mathrm{dL}$ \\
\hline
\end{tabular}


ization and thus neural conduction [1]. Binding to the "inner vestibule" of the sodium channel, LAs inhibit the conformational change required for channel activation [2]. The ability of LAs to cause neural blockade is affected by the nerve fiber type, the sodium channel isoform, and the state of the channel [2]. Blockade is "use dependent" as LAs have a higher affinity for sodium channels in the open or inactivated state as compared to the resting state [3]. Thus, repeated depolarizations increase the fraction of drugbound channels. Small myelinated axons are most sensitive to LA blockade followed by large myelinated axons with small non-myelinated axons being the least sensitive [2]. In addition to sodium channel blockade, LAs also decrease catecholamine-dependent production of cAMP, block $\beta 2$ adrenergic receptors, block L-type calcium channels, and may interfere with cellular energy metabolism [4-7].

There are many clinically useful LAs which are classified by an esther or amide link between a hydrophilic amine end and a lipophilic aromatic end. Amide-linked LAs include bupivicaine, dibucaine, lidocaine, prilocaine, and others. Amide-linked LAs can be further divided into aminoacyl or aminoakyl amides, based on the structure of the amide bond [8]. Dibucaine (2-butoxy- $N$-[2-(diethylamino)ethyl]-4-quinolinecarboxamide), an aminoakyl LA, was first used clinically in 1932 and is also known as cincaine, cinchocaine, sovcain, percaine, and various other names [3]. It is available as an ointment $(0.25-1 \%)$, cream $(0.25-1 \%)$, aerosol $(0.25-1 \%)$, solution $(0.25 \%)$, or suppository $(2 \%)$ intended to treat discomfort associated with sunburn, eczema, minor rashes, minor scratches, insect bites, or poison ivy used alone or in combination with other active ingredients to treat pain associated with hemorrhoids or other anorectal disorders [2]. Topical dibucaine ointments are marketed directly to consumers in the USA and are available without prescription. In addition, dibucaine is used in combination with secobarbital sodium as a euthanasia solution for veterinary species in the UK and Ireland and as a preservative-free solution for spinal anesthesia (outside of the USA). An injectable form of dibucaine has been previously approved for use in humans by the FDA but is not commercially available in the USA [9].

For stability, most LAs are formulated as a hydrochloride salt in which the LA is in its water soluble (ionized) form; therefore, intact skin is an effective barrier to absorption [8]. To overcome this barrier, a mixture of lidocaine and prilocaine, both in a pure base (non-ionized) form, with unique physical properties has been developed. This mixture plus an inert vehicle produces a cream (eutectic mixture of local anesthetics or EMLA) that is able to penetrate intact skin and anesthetize dermal and subcutaneous sensory nerve endings [8]. Topical application of a LA on abraded skin or mucous membranes or covering the medication with an occlusive dressing will increase systemic absorption [10]. When injected into a tissue space or after mucosal application, LAs are quickly absorbed systemically and reach peak concentrations in 5 to $25 \mathrm{~min}$ [1]. The bioavailability of LAs after mucosal application depends on total dose, mucosal integrity, presence or absence of hyperemia, and contact time [1]. Quick absorption when applied to mucosal membranes, like the oral mucosa, explains the rapid onset of clinical signs in this case.

Once absorbed systemically, amide-linked LAs are metabolized in the liver by cytochrome P450 enzymes [3]. Amide-linked LAs are more slowly metabolized than esterlinked LAs, which are metabolized mainly by plasma esterases. Dibucaine is excreted both in the urine and bile [11]. In rats, unchanged drug has a blood half-life of $11.6 \mathrm{~min}$, and metabolites have a biphasic half-life of $37.7 \mathrm{~min}$ and $11.2 \mathrm{~h}$ [11]. Major urinary metabolites differ between species [12]. Although the biologic activity of dibucaine metabolites remains unknown, metabolites of other amide-linked LAs are reported to contribute to toxicity [3]. In this case, resolution of neurologic signs was relatively soon after ingestion $(60 \mathrm{~min})$, indicative of a short plasma half-life of unchanged drug or drug levels barely reaching that required for intoxication and either clinically insignificant biologic activity or clinically insignificant levels of metabolites.

Local anesthetic toxicity occurs due to unintentional intravascular injection or direct over dosage via peripheral injection or, in rare cases, via topical or oral exposure. The acute oral LD50 of dibucaine was found to be $42 \mathrm{mg} / \mathrm{kg}$ in birds, and in a case series of three children who ingested a lethal dose of dibucaine ointment, ingested amounts were estimated to be 15 and $19 \mathrm{mg} / \mathrm{kg}$ with one child ingesting an unknown amount $[13,14]$. Only one child vomited after ingestion. In the present case, the patient ingested approximately $38 \mathrm{mg} / \mathrm{kg}$ of dibucaine although much of the ingested ointment was believed to have been vomited.

Generally, LAs are safe drugs when administered where intended and at appropriate doses, but with over dosage gastrointestinal, neurologic, and cardiac signs can occur. Gastrointestinal signs occur before or after neurologic signs which precede cardiovascular dysfunction [15]. de Jong et al. described one exception in which cats administered subconvulsant doses of bupivicaine and etidocaine consistently had cardiac arrhythmias [16]. Although not reported with dibucaine toxicosis, amide-linked LAs can cause methemoglobinemia, which is most commonly seen with prilocaine $[3,10,15]$. The clinical signs seen in this case are presumed to be the effects of dibucaine. The inactive ingredients found in the ointment can cause gastrointestinal disturbances, which probably requires ingestion of larger amounts than were ingested in this case [17]. In addition, the neurologic signs seen in this case are not reported with any of the inactive ingredients [17]. 
Drugs that inhibit sodium channels are only able to depress neural tissue activity [18]. The ability of LAs to cause apparent neural excitation (i.e., seizures, twitching) can be explained by the fact that excitatory cortical neurons are more resistant to the effects of LAs than inhibitory cortical neurons [19]. With the blockade of inhibitory cortical neurons, excitatory cortical neurons function unopposed, resulting in neural excitation. In addition to inhibitory cortical neuron blockade, net release of glutamate, a stimulatory amino acid, may also contribute to the initial central nervous system excitation [2]. As drug levels increase, excitatory cortical neurons are also inhibited which, combined with glutamate receptor desensitization and transmitter depletion, eventually leads to CNS depression [2]. In humans, neurologic effects of LA toxicity initially cause numbness of the tongue and mouth followed by lightheadedness, dizziness, tinnitus, vision disturbance, and slurred speech $[10,18]$. At higher drug levels, muscle twitching, irrational conversation, and unconsciousness are seen $[10,15,18]$. As drug concentrations continue to increase, neurologic signs progress to seizures, coma, and respiratory arrest $[15,18]$. If systemic levels of the LA rise quickly, the early signs of neurologic dysfunction might not be recognized. In children that have ingested lethal doses of dibucaine ointment, neurologic dysfunction presented as some combination of lethargy, ataxia, unconsciousness, and seizures [14]. The neurologic manifestations of dibucaine toxicosis in this case included ptyalism, disorientation, muscle fasciculations, and ataxia. The ptyalism seen in this case could be due to nausea but is more likely due to the numbness of the cheeks and tongue, which is a local and not central nervous system effect [18].

The cardiotoxicity of different LAs varies and is directly related to the LA potency [20]. Deleterious cardiovascular effects of LAs generally require higher drug concentrations than are required to cause neurologic signs $[15,21]$. In dogs, after rapid IV administration, the cumulative dose required to cause cardiac depression and death was 3.5, 5.1, 6.7, and 4.1 times the convulsant dose for lidocaine, etidocaine, tetracaine, and bupivicaine, respectively [21]. Local anesthetic intoxication alters the electrophysical and mechanical activity of the myocardium in addition to affecting the peripheral vasculature [22]. In addition to sodium and L-type calcium channel blockade, LAs inhibit catecholamine-dependent cAMP production and might interfere with cellular energy production, contributing to cardiotoxicity $[4,6,7]$. Automaticity in the SA and AV nodes and conduction through the Purkinje fibers and ventricular myocardium are decreased $[23,24]$. As a result of the conduction disturbances, susceptibility to reentry arrhythmias is increased [23, 24]. In addition to conduction disturbances, myocardial contractility is decreased, which leads to decreased cardiac output [20, 24]. Early ECG changes include bradycardia, a prolonged $\mathrm{P}-\mathrm{R}$ interval, and a wide QRS complex [25]. Other ECG changes can include ventricular tachyarrhythmias, asystole, and conduction blocks [26]. After intravenous overdose of bupivicaine, in anesthetized dogs, the most common arrhythmia was a slow idioventricular rhythm with electromechanical dissociation: ventricular tachycardia was seen in two of six dogs [27]. In cats, sub-convulsant doses of LAs caused aberrant intraventricular conduction and nodal and ventricular arrhythmias [16]. The effect of LAs, with the exception of cocaine, on peripheral vasculature is biphasic with subtoxic levels causing vasoconstriction and higher drug levels causing vasodilation [28]. Vasodilation may be caused by nitrous oxide (NO) synthase-dependent NO production induced by LAs [29]. Although vasodilation occurs, a study in dogs found that hypotension was primarily the result of myocardial depression and not a decrease in peripheral vascular resistance [20]. In children that have ingested a lethal dose of dibucaine ointment, cardiovascular effects included wide complex bradycardia which in some cases was irregular, ventricular tachycardia, ventricular fibrillation, and cardiopulmonary arrest [14]. Cardiovascular dysfunction was not detected in the present case as no arrhythmias were seen on ECG and systemic blood pressure was normal. Although myocardial contractility was not assessed via echocardiography, with the absence of hypotension or other signs of cardiovascular dysfunction, myocardial contractility was presumed to be normal. If clinical progression of oral dibucaine toxicosis in dogs is similar to clinical progression in humans, then more severe neurologic signs would be expected before significant cardiovascular dysfunction [14]. It is likely that the presence of neurologic signs without cardiovascular dysfunction is directly related to drug levels, although dibucaine levels were not measured in this case.

In humans, the recommended treatment after ingestion of $1 \%$ dibucaine ointment includes consuming two glasses of water and inducing vomition [30]. Vomition was not induced in this case as the patient had previously vomited multiple times. With any LA toxicosis if neurologic or cardiovascular dysfunction is present, immediate treatment is necessary. Maintenance of a patent airway and respiratory support is essential. Studies using cats, dogs, and sheep have shown that LA intoxication is more severe in the presence of acidosis (respiratory or metabolic), hypercarbia, and hypoxia [31-34]. Thus, avoidance of hypoventilation causing respiratory acidosis and hypoperfusion causing metabolic acidosis is key. Seizures can exacerbate hypercapnia and acidosis. Thus, early and appropriate treatment of seizure activity is vital $[35,36]$. Seizures can be self limiting but may require a benzodiazepine, propofol, or barbiturate, which usually are effective $[3,26]$. If the patient requires artificial ventilation, monitoring end-tidal 
carbon dioxide concentration and acid-base status via arterial blood gas analysis is recommended. Blood electrolyte levels including potassium should be monitored as hyperkalemia has been shown to increase LA toxicity [37]. Continuous or frequent intermittent monitoring of systemic blood pressure and ECG is also prudent if present cardiopulmonary arrest should be treated with standard cardiopulmonary resuscitation, which historically has been relatively refractory to treatment $[26,38]$. The most effective positive ionotrope, vasopressor, or antiarrhythmic remains unknown, although correction of hypotension and arrhythmias leading to hypoperfusion appears to be essential [16, 31-33]. Kasten et al. described effective cardiovascular resuscitation after bupivicaine overdose in anesthetized dogs using open-chest cardiac massage, bretylium, atropine, epinephrine, and intravenous crystalloid fluids [27]. Hypotension could be treated with epinephrine or norepinephrine, although amrinone was found to be superior to epinephrine at reversing bupivicaine-induced cardiovascular depression in dogs [37, 38]. Amrinone also improved cardiac output, mean arterial pressure, and heart rate in severe bupivicaine intoxication in pigs [38]. Amrinone may be more effective than epinephrine due to its ability to increase cAMP independent of the $\beta$-adrenergic receptor. The administration of ephedrine-corrected hypotension and arrhythmias in cats administered supraconvulsant doses of lidocaine [16]. Bradycardia can be treated with atropine or may resolve with the administration of epinephrine, norepinephrine, or amrinone [27, 37, 39]. Further use of LAs as antiarrhythmics (such as lidocaine) should be avoided, and arrhythmias might be better treated with bretylium, phenytoin, or amiodarone [25, 37-39]. While not readily available to veterinary patients, the Association of Anesthetists of Great Britain and Ireland (AAGBI) recommends considering cardiopulmonary bypass, which has been used successfully in bupivicaine toxicosis [26, 40]. Another novel treatment includes the administration of insulin and glucose with or without potassium, which decreased the time for mean arterial pressure, cardiac output, heart rate, and mixed venous oxygen saturation to improve to prebupivicaine levels, after induced bupivicaine toxicosis in dogs [41]. With oral intoxication, although only anecdotally beneficial, activated charcoal can be administered. Care must be taken to only administer charcoal to a patient with a protected airway (normal gag reflex or tracheal intubation). Charcoal was administered in this case as the patient was conscious with a normal gag reflex.

Lipid infusion in the treatment of LA toxicosis is promising [42]. There are multiple human case reports in which lipid infusion was beneficial in refractory cardiovascular and CNS dysfunction caused by LAs (other than dibucaine) [43, 44]. Prospective controlled studies in dogs and rats show that lipid infusion is beneficial in the treatment of LA toxicosis by greatly improving survival and increasing the dose of LA required to cause intoxication, respectively [45, 46]. Lipid infusion is believed to extract LA from plasma or tissue, counteract myocardial fatty acid oxidation, or both [45, 47]. Dogs administered a toxic dose of bupivicaine were administered a $4 \mathrm{ml} / \mathrm{kg}$ bolus of a $20 \%$ lipid solution followed by $0.5 \mathrm{~mL} / \mathrm{kg} / \mathrm{min}$ constant rate infusion for $10 \mathrm{~min}$ during intrathoracic cardiopulmonary resuscitation [45]. The AAGBI set guidelines for administering lipid emulsion in severe LA toxicosis, which include administering 20\% lipid solution (Intralipid ${ }^{\circledR}$, Fresenius Kabi, Uppsala, Sweden) at $1.5 \mathrm{ml} / \mathrm{kg}$ over $1 \mathrm{~min}$ followed by $0.25 \mathrm{ml} / \mathrm{kg} / \mathrm{min}$ over $20 \mathrm{~min}$ [26]. If adequate circulation is not restored, repeating two boluses at 5 -min intervals $(1.5 \mathrm{ml} / \mathrm{kg})$ and administering $0.5 \mathrm{ml} / \mathrm{kg} / \mathrm{min}$ over $10 \mathrm{~min}$ is recommended [26]. Infusion is to be continued until stable and adequate circulation has been restored.

\section{Conclusion}

Oral dibucaine toxicosis in the dog is clinically similar to LA toxicosis in humans. Oral dibucaine toxicosis in the dog initially manifests as vomiting and ptyalism and can quickly progress to neurologic and cardiovascular dysfunction, although cardiovascular dysfunction was not noted in this case. Dibucaine commonly found as a topical medication presents a real and potentially serious toxicological risk for pets and thus should be stored in a secure location.

\section{References}

1. Berde CB (1993) Toxicity of local anesthetics in infants and children. J Pediatr 122:S14-S20

2. Strichartz GR, Berde CB (2005) Local anesthetics. In: Miller RD (ed) Miller's anesthesia, 6th edn. Elsevier, Philadelphia, pp 573603

3. Heavner JE (2007) Local anesthetics. Curr Opin Anaesthesiol 20:336-342

4. Butterworth J, Brownlow RC, Leith JP, Prielipp RC, Cole LR (1993) Bupivicaine inhibits cyclic 3', 5' -adenosine monophosphate production. Anesthesiology 79:88-95

5. Butterworth J, James RL, Grimes J (1997) Structure-affinity relationships and stereospecificity of several homologous series of local anesthetics for the $\beta 2$-adrenergic receptor. Anesth Analg 85:336-342

6. Zapata-Sudo G, Trachez MM, Sudo RT, Nelson TE (2001) Is comparative cardiotoxicity of $\mathrm{S}(-)$ and $\mathrm{R}(+)$ bupivicaine related to enantiomer-selective inhibition of L-type $\mathrm{Ca}^{2+}$ channels? Anesth Analg 92:496-501

7. Eledjam JJ, de La Coussaye J, Brugada J, Bassoul B, Gagnol JP, Fabregat JR et al (1989) In vitro study on mechanisms of bupivicaine-induced depression of myocardial contractility. Anesth Analg 69:732-735

8. de Jong R (1994) Local anesthetics. Mosby, St. Louis, pp 173-206 
9. US Food and Drug Administration [webpage on internet]. Dibucaine drug details [updated daily]. Available from: http:// www.accessdata.fda.gov.

10. Golembiewski J (2007) Local anesthetics. J Perianesth Nurs 22:285-288

11. Igarashi K, Kasuya F, Fukui M (1989) Metabolism of dibucaine. II. Disposition and metabolism of dibucaine in rats. J PharmcobioDyn 12:523-529

12. Igarashi K, Kasuya F, Fukui M (1983) Metabolism of dibucaine: isolation and identification of urinary basic metabolites in the rat, rabbit and man. J Pharmacobio-Dyn 6:538-550

13. MSDS Dibucaine. [webpage on internet]. [updated October 9, 2005] Available from: http://sciencelab.com

14. Dayan PS, Litovitz TL, Crouch BI, Scalzo AJ, Klein BL (1996) Fatal accidental dibucaine poisoning in children. Ann Emerg Med 28:442-445

15. Becker DE, Reed KL (2006) Essentials of local anesthetic pharmacology. Anesth Prog 53:98-109

16. de Jong RH, Ronfeld RA, DeRosa RA (1982) Cardiovascular effects of convulsant and supraconvulsant doses of amide local anesthetics. Anesth Analg 61:3-9

17. MSDS, acetone sodium bisulphate, anhydrous lanolin, and white petroleum [webpage on internet]. Available from: www.msds.com

18. Scott DB (1986) Toxic effects of local anaesthetic agents on the central nervous system. Br J Anaesth 58:732-735

19. Tanaka K, Yamasaki M (1966) Blocking of cortical inhibitory synapses by intravenous lidocaine. Nature 209:207-208

20. Liu P, Feldman HS, Covino BM, Giasi R, Covino BG (1982) Acute cardiovascular toxicity of intravenous amide local anesthetics in anesthetized ventilated dogs. Anesth Analg 61:317-322

21. Liu PL, Feldman HS, Giasi R, Patterson MK, Covino BG (1983) Comparative CNS toxicity of lidocaine, etidocaine, bupivicaine, and tetracaine in awake dogs following rapid intravenous administration. Anesth Analg 62:375-379

22. Altman RS, Smith-Coggins R, Ampel LL (1985) Local anesthetics. Ann Emerg Med 14:1209-1217

23. Moller RA, Covino BG (1993) Cardiac electrophysiologic effects of articaine compared with bupivicaine and lidocaine. Anesth Analg 76:1266-1273

24. Reiz S, Nath S (1986) Cardiotoxicity of local anesthetic agents. Br J Anaesth 58:736-746

25. Jackson T, McLure HA (2006) Pharmacology of local anesthetics. Opthalmol Clin N Am 19:155-161

26. The Association of Anesthetists of Great Britain \& Ireland [webpage on internet]. Guidelines for the management of severe local anesthetic toxicity [Updated 2007]. Available from: http:// www.aagbi.org

27. Kasten GW, Martin ST (1985) Successful cardiovascular resuscitation after massive intravenous bupivicaine over dosage in anesthetized dogs. Anesth Analg 64:491-497

28. Mama KR, Steffey EP (2001) Local anesthetics. In: Adams HR (ed) Veterinary pharmacology and therapeutics, 8th edn. Iowa State University Press, Ames, pp 343-359

29. Mamiya K, Tomoda MK, Edashige K, Ueda W, Manabe M (1995) Local anesthetics enhance nitric oxide production by human peripheral neutrophils. Physiol Chem Phys Med 27:111-119
30. MSDS \#05A Dibucaine Ointment USP 1\% [webpage on internet]. [updated September 1, 2005]. Available from: http://www. msdsonline.com.

31. Englesson S (1974) The influence of acid-base changes on central nervous system toxicity of local anaesthetic agents I. Acta Anaesthesiol Scand 18:79-87

32. Englesson S, Grevsten S (1974) The influence of acid-base changes on central nervous system toxicity of local anesthetic agents II. Acta Anaesthesiol Scand 18:88-103

33. Englesson S (1966) Intravenous toxicity-subjective symptoms and acid-base influences on the toxicity of local anaesthetic agents. Acta Anaesthesiol Scand 25:28-33

34. Rosen MA, Thigpen JW, Shnider SM, Foutz SE, Levinson G, Koike M (1985) Bupivicaine-induced cardiotoxicity in hypoxic and acidotic sheep. Anesth Analg 64:1089-96

35. Moore DC, Crawford RD, Scurlock JE (1980) Severe hypoxia and acidosis following local anesthetic-induced convulsions. Anesthesiology 53:259-260

36. Feldman HS, Arthur GR, Pitkanen M, Hurley R, Doucette AM, Covino BG (1991) Treatment of acute systemic toxicity after the rapid intravenous injection of ropivicaine and bupivicaine in the conscious dog. Anesth Analg 73:373-384

37. Cox B, Durieux ME, Marcus MAE (2003) Toxicity of local anesthetics. Best Pract Res Clin Anaesthesiol 17:111-136

38. Saitoh K, Hirabayashi Y, Shimizu R, Fukuda H (1995) Amrinone is superior to epinephrine in reversing bupivicaine-induced cardiovascular depression in sevoflurane-anesthetized dogs. Anesthesiology 83:127-133

39. Lindgren L, Randell T, Suzuki N, Kytta J, Yli-Hankala A, Rosenberg PH (1992) The effect of amrinone on recovery from severe bupivicaine intoxication in pigs. Anesthesiology 77:309-315

40. Soltesz EG, van Pelt F, Byrne JG (2003) Emergent cardiopulmonary bypass for bupivicaine cardiotoxicity. J Cardiothorac Anesth 17:357358

41. Cho HS, Lee JJ, Chung IS, Shin BS, Kim JA, Lee KH (2000) Insulin reverses bupivicaine-induced cardiac depression in dogs. Anesth Analg 91:1096-1102

42. Corman SL, Skledar SJ (2007) Use of lipid emulsion to reverse local anesthetic-induced toxicity. Ann Pharmacother 41:1873-1877

43. Warren JA, Thoma RB, Georgescu A, Shah SJ (2008) Intravenous lipid infusion in the successful resuscitation of local anesthetic-induced cardiovascular collapse after supraclavicular brachial plexus block. Anesth Analg 106:15781580

44. Litz RJ, Roessel T, Heller AR, Stehr SN (2008) Reversal of central nervous system and cardiac toxicity after local anesthetic intoxication by lipid emulsion injection. Anesth Analg 106:1575-1577

45. Weinberg G, Ripper R, Feinstein DL, Hoffman W (2003) Lipid emulsion infusion rescues dogs from bupivicaine-induced cardiac toxicity. Reg Anesth Pain Med 28:198-202

46. Weinberg G, VadeBoncouer T, Ramaraju GA, Garcia-Amaro MF, Cwik MJ (1998) Pretreatment or resuscitation with a lipid infusion shifts the dose-response to bupivicaine-induced asystole in rats. Anesthesiology 88:1071-1075

47. Picard J (2006) Lipid emulsion to treat overdose of local anaesthetic: the gift of glob. Anaesthesia 61:107-109 